\title{
EUROPEAN PROCEDURES TO RIVER QUALITY ASSESSMENT
}

\section{NADDEO* \\ T. ZARRA \\ V. BELGIORNO}

Selected from papers presented in $9^{\text {th }}$ International Conference on Environmental Science and Technology (9CEST2005)

1-3 September 2005, Rhodes island, Greece

\author{
Department of Civil Engineering \\ University of Salerno \\ 84084 Fisciano(SA), Italy
}

*to whom all correspondence should be addressed e-mail:vnaddeo@unisa.it

\section{ABSTRACT}

The EU directive (2000/60/EC) known as the Water Framework Directive (WFD), identifies new methodology for monitoring and improving of surface water quality in the territory. This includes controlling land-based pollutants as well as defining the constraints for territorial planning. It is, therefore, necessary to know in detail the surface water quality in order to estimate the possible consequences of a either new civil or industrial activity to settle in the territory. Thus, investigating methodologies, data analysis procedures and water quality management tools need to be well defined. The new EU water framework directive institutionalizes ecosystem-based objectives and planning processes at the level of the hydro-graphic basin as the basis for water resource management. It underlines the need for developing adequate biological and ecotoxicological tests. An ample management strategy of the use of natural resources from basin ecosystems is also needed. Management programs require a multidisciplinary approach based on a systematic monitoring of key biological and chemical physical parameters. On the other hand, only a few suggestions have been proposed for the tools needed the interpretation of the large amount of environmental data required to obtain the information for a correct basin management. The creation of innovative decision making tools for sustainable basin resource utilization is an important challenge for the future application of the directive.

The aim of this study is to describe the implementation of WFD in European Country, with a discussion of a case study. To assess the chemical and the ecological status of the surface water according to WFD-2000, the approache of the EU were discussed. The influences of the assessment methods on the water quality classes are also showed. In this context, a brief overview of chemical, physical, and biological monitoring methods, problems related to implementation of the new directive is done. Salerno district, the biggest province $\left(4922 \mathrm{Km}^{2}\right)$ in Southern Italy, was the case study for which water quality monitoring has been performed on Sele river (Parco del Cilento). Within the period from February 2001 to April 2004, 6 sampling station were monthly monitored and the water quality of the rivers was analyzed. The flow of the river as well as physical $(\mathrm{pH}$, water and air temperatures), chemical (suspended solids, $\mathrm{NH}_{4}-\mathrm{N}, \mathrm{NO}_{2}-\mathrm{N}, \mathrm{NO}_{3}-\mathrm{N}$, dissolved oxygen (DO), chemical oxygen demand (COD), biochemical oxygen demand $\left(\mathrm{BOD}_{5}\right)$, phosphate concentration) and biological (Escherichia coli and the Extended Biotic Index (EBI)) parameters were monitored.

The results obtained allowed us to define the chemical, physical and biological water quality of the Sele river. At the same time, its classification according to the main WFD outlines was done. A correlation between biologically determined quality classes and chemical measurements was observed. The conclusion was that the parameters have to 
be measured carefully to provide unique definition of environmental status according to WDF-2000 for a water resource, hence, uniform and unbiased water quality assessment in the EU will be obtained.

KEYWORDS: chemical status, ecological status, river, surface waters, water framework directive.

\section{INTRODUCTION}

The EU directive 2000/60/EC, also known as the Water Framework Directive (WFD), identifies new processes for developing and safeguarding the territory through surface water quality characterization. This implies controlling pollution loads as well as defining the constraints that are connected to territorial planning. It will be therefore necessary to know in detail the surface water quality in order to forecast the possible consequences of an either new civil or industrial site. Investigating methodologies, data analysis procedures and water quality management tools will be needed to be defined for European Countries.

The aim of this study is to describe the WFD in European Countries and it's implementation in Italy (Legislative Decree 11.05.1999 n. 152), with a discussion of a case study.

The results obtained have allowed a preliminary definition of the chemical, physical and biological water quality of a river located in a protected area of Southern Italy (Parco del Cilento) as well as its classification according to the main WFD outlines.

\section{EUROPEAN WATER LEGISLATION}

The WFD proposes to introduce a strategic legislative framework designed to tie together the various strands of water policy and provide a more holistic and integrated approach to water management and conservation. The WFD will also rationalise existing water legislation through the eventual replacement of a number of new directives relating to surface water abstraction, measurement of water quality, freshwater fisheries, shellfish waters, groundwater and dangerous substances.

The underlying aims of the WFD are to:

- provide an integrated system of water management based on hydrological catchments rather than political or administrative boundaries (Art. 3);

- set environmental objectives to ensure that all waters - rivers, lakes, coastal waters and ground-waters - achieve "good status" and prevent deterioration of such waters (Art. 4);

- introduce a "combined approach" to pollution control (Art. 10);

- $\quad$ encourage sustainable water use (Arts 5, $7 \&$ 9);

- contribute to mitigating the effects of floods and droughts (Art. 1) and

- $\quad$ ensure active stakeholder \& community involvement (Art. 14).

Europe will be divided into a series of river basin districts - some of which will traverse national frontiers. River Basin Management Plans will be prepared for each district that will incorporate a programme of measures to meet specific environmental objectives set for each river basin. Public consultation programmes will be integral to the identification of significant water management issues and the development of River Basin Management Plans $[1,2,3]$.

The timeframe for implementation of the directive is relatively short, spoken in terms of previous European water policies (Figure 1).

Waters will be classified as "high", "good", "fair", "poor" or "bad" status based on a range of ecological, chemical and hydrological criteria. The overall plan is for 'good' ecological and 'good' chemical status to be met for all surface waters by the end of 2015. Most Member States already incorporate EU chemical quality standards for particular 
pollutants. To obtain good chemical status these standards must be complied with National and European regulations.

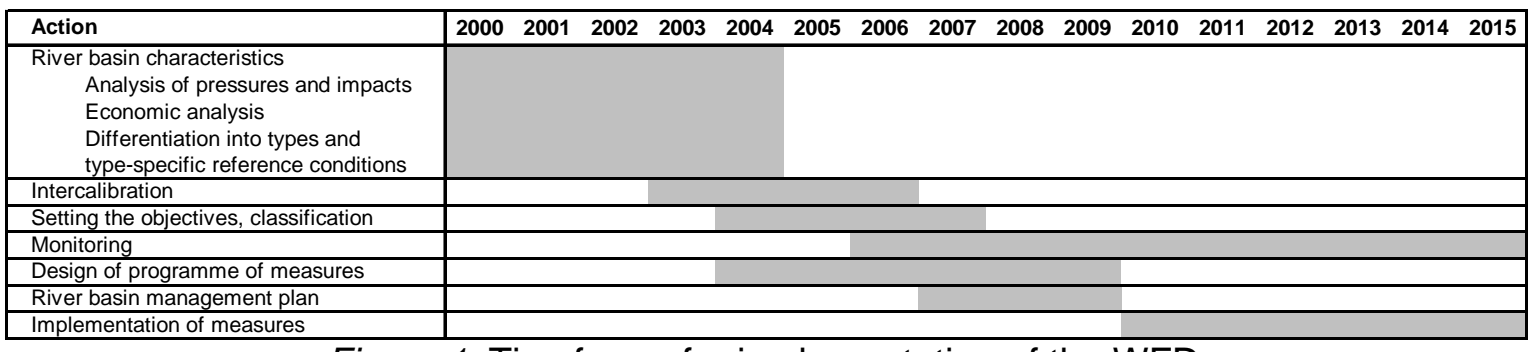

Figure 1. Timeframe for implementation of the WFD

The integration of ecological indicators with more traditional water quality and quantity objectives will be a much bigger challenge. The WFD states that ecological status will be assessed through a measuring a combination of biological, hydromorphological and chemical elements including pollution levels [4,5,].

This will require many Member States to rethink their current water monitoring and management strategies. In some countries like Austria, Germany and Sweden the demands of the EU Water Framework Directive have been mostly achieved if we look at the complex data series of hydro morphology and chemistry $[7,8]$. However, there are still some difficulties with biological attributes $[9,10,11]$.

Through the development and implementation the European Union hopes to introduce uniform classification proceedings in big water courses in a trouble free manner through the efficient use of development and implementation strategies.

\section{IMPLEMENTATION OF WFD IN EUROPEAN COUNTRIES}

The Water Framework Directive cannot be directly applied in the river basin districts because of the complexity of its regulations and ambitious standards set out in the appendixes.

Many of the tasks, such as the elaboration of significance criteria, the typology, the setting of reference conditions and above all the development of an assessment procedure for the determination of the ecological quality of rivers, lakes, transitional waters and coastal waters, have not previously been addressed by water authorities [12]. The necessary work has been started in the member states and involves enormous financial and organizational effort.

Like written in article 3 of the Water Framework Directive, the member states have to find "appropriate administrative arrangements", including the identification of appropriate competent authorities for the application of the rules of this Directive in their national area [13]. The member states have a liberty to find there own competent authority to implement the Directive. The coordination is particularly important and not so much the form itself.

This principle is mandatory for all other activities in the Water Framework Directive, like consultation of the public, development of national guidelines and discussions on the institutional framework of launching research programs.

Pilot activities have been started in different countries for testing specific elements of the Directive and to analyze the overall planning process in more detail.

In May 2001 the signer of the Water Framework Directive developed and agreed to a common implementation strategy $[14,15,16]$. The main objective of this strategy is to provide support to the implementation of the Water Framework Directive by developing coherent understanding and guidance on key elements of the Directive.

Key principles in this common strategy include sharing information and experiences, the development of common methodologies and approaches, and the involvement of experts and stakeholders from candidate countries. In the context of this common implementation strategy, a series of working groups and joint activities have been launched for the 
development and testing of non-legally binding guidance. A strategic coordination group oversees these working groups and reports directly to the water directors of the European Union Commission that function as the decision body for the implementation strategy.

Figure 3 provides an overview on the state-of-play of transposition and reporting, in the form of a simple scoreboard. The WFD Scoreboard gives a quick overview on the performance of the Member States as regards the legal transposition and the implementation elements of the Water WFD which have deadlines during 2004 and 2005. (Note that the information only reflects whether or not a Member State has delivered as required by the reporting obligation. It does not make any judgement on the quality of the report.)
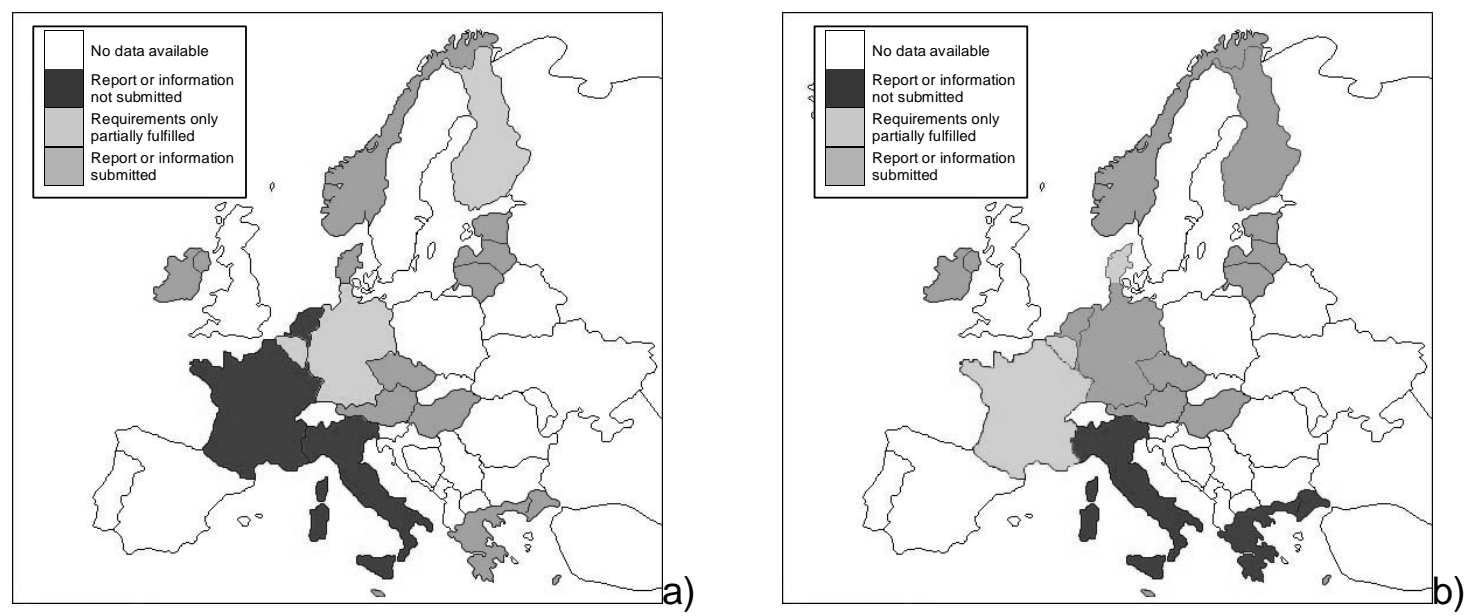

Figure 2. WFD overview on the state-of-play of transposition and reporting on the performance of the Member States respect to: a) Notification, Art.29; b) River basin district report

\section{ITALIAN APPROACH TO RIVER QUALITY ASSESSMENT}

The current Italian normative regarding the safeguard and management of water quality is the Legislative Decree 11.05.1999 n. 152 (D.L. 152/99), based on both EU directives 91/271/CEE and 91/979/CEE and elaborated on the preliminary draft of the WFD.

The D.L. 152/99 defines the safeguarding of all waters, surface, marine and underground following the main WFD objectives.

D.L. 152/99 identifies the minimum environmental status as well as the quality status for waters with specific uses. The environmental quality objectives are defined taking the ability of the water body to maintain its natural self depuration processes into consideration as well as its capacity to support wildlife and vegetation, that can greatly influence both quantitatively and qualitatively the water body and ecosystem.

The first step has the aim of supplying the base and support tools required for designing a suitable system for monitoring and controlling surface water quality. This is followed by the identification and physical characterisation of the hydrological basin using cartographic maps as well as any other historical data available on the basin under study. Any alterations, natural or anthropic (depuration plants, sewerage etc) and the state of the ecosystem are subsequently identified. Thematic maps are then drawn up based on the information obtained, in order to have a complete picture of the territory.

The thematic maps drawn up and the data obtained are useful for subdividing the rivers into homogenous reaches, therefore identifying monitoring sections. The number and position of the monitoring stations is based upon the minimum requisites in accordance to the law as well as by the presence of any constraining conditions that influence sample taking and subsequent analysis.

The monitoring frequency must include at least one sample per month for the macroindex parameters and one per season for the biological parameters, as set out in Italian norm with reference to the initial monitoring phase. Once the monitoring stations have 
been identified along with the relative sample frequencies for each parameter (macroindex, IBE, micro-contaminant), the water quality monitoring can begin.

The "environmental status" of every single homogenous reach is then defined on the basis of the data obtained. The environmental status is defined using both the biological and chemical definitions, with the first being the synthetic expression of the aquatic ecosystem complexity, while the latter is based upon the presence of dangerous chemicals (micro-contaminants) that must be kept under control.

The Italian normative, conforming to the WFD, foresees at least a "good" status for the water bodies as well as a safeguarding and recovery plan, that is subsequently adapted to the classification obtained. A recovery of quality is necessary if the environmental status is lower than "good" with the aim of improving water quality. If the environmental status is "good" or "high" it is important to maintain this level with an appropriate safeguard plan and any necessary interventions.

\subsection{Case study}

The area of the case study include the Persano Park, a protected area in Southern Italy, in which water quality monitoring has been carried out on the Sele river (Figure 4).

The water basin of the Sele river covers a surface of $600 \mathrm{~km}^{2}$; the overall length of the main tributary is $64 \mathrm{~km}$. The river, predominantly creek state, is made up of a gravelypebbly bottom in the downstream part, with broad riverbed and small riverside in the intermediate reach, while it is built-in and calcareous formations exist in the upstream reach where the riverbed has a width that is seldom grater than $5 \mathrm{~m}$.

\section{ANALYTICAL METHODS}

The number and location of the sampling sites was established taking the presence of urban settlements, production plants and all polluting loads into consideration. The sampling sites were also set up at a suitable distance from the source of emission that guaranteed a complete mix of the water, with the aim of evaluating the river water quality and not that of the influent. The location of the sites was influenced by technical as well as operative constraints (e.g. difficulty in sample taking). 6 sampling sites were set up on the basin of the river Sele.

144 samples in 24 months were collected and the water quality of the Sele river was analyzed, monitoring river flow, $\mathrm{pH}$, suspended solids (SS), water temperature, air temperature, $\mathrm{NH}_{4}-\mathrm{N}, \mathrm{NO}_{2}-\mathrm{N}, \mathrm{NO}_{3}-\mathrm{N}$, dissolved oxygen (DO), chemical oxygen demand $(\mathrm{COD})$, biochemical oxygen demand $\left(\mathrm{BOD}_{5}\right)$, phosphate concentrations, Escherichia coli, Extended Biotic Index (IBE), and micro-contaminants during the period from February 2001 to April 2004.

The methodologies used to analytically define the macro-index, were those set out by Italian Research Council (IRSA-CNR,1994), and was carry out by ARPAC (Italian National Environmental Protection Agency for Campania Region).

The water samples were collected in 2 litre glass bottles, transported to the laboratory in thermal bags and analysed in the same day. The $\mathrm{pH}$ level, the air temperature, the water temperature and dissolved oxygen were all measured on site.

\section{RESULTS}

The analytical results of the monitoring activity were used to define the ecological and chemical state according the WFD directive. With regard to the latter, the analysis of the micro-contaminants was carried out for each sampling site, the result are showed in Figure 3. 

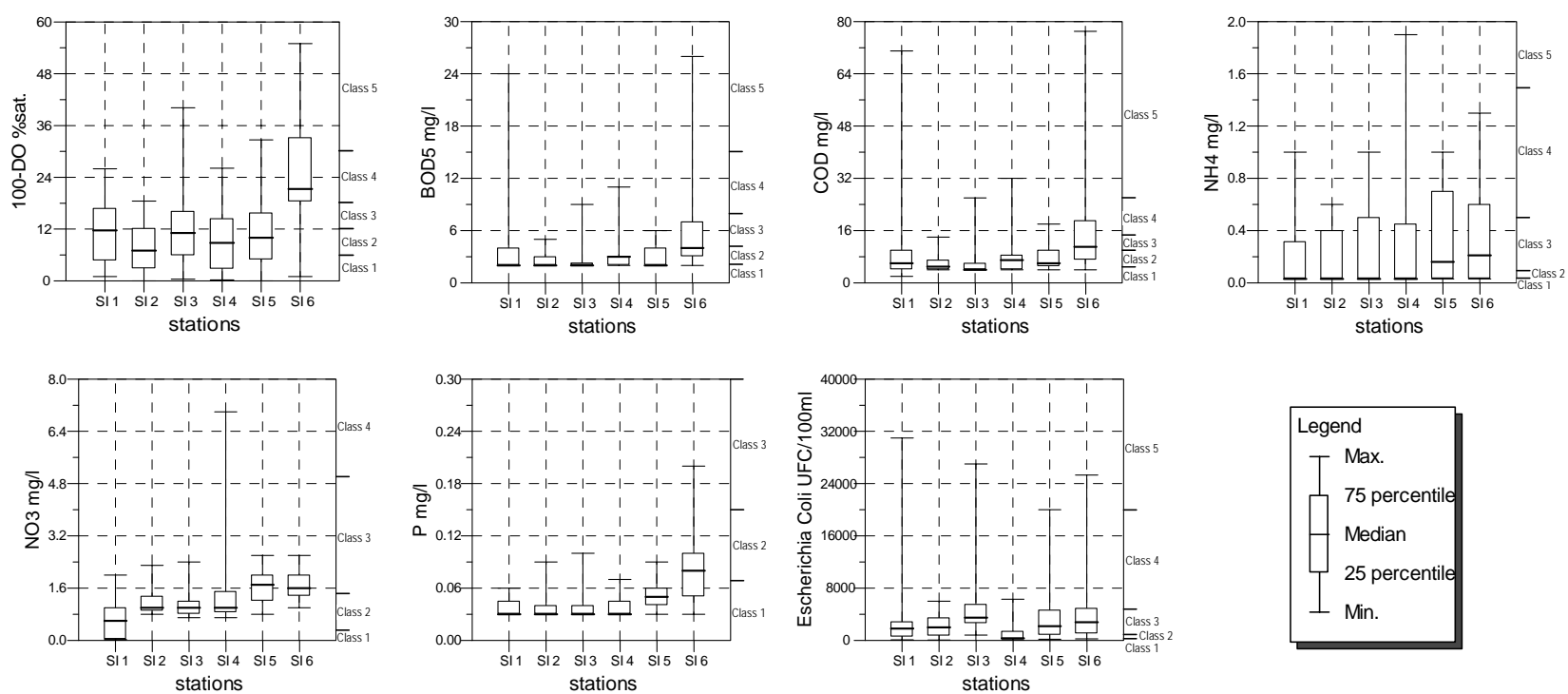

Figure 3. Macro-indexes Box and Whisker plots for each sampling station of Sele river from February 2001 to April 2004

The operation, repeated for each homogeneous part of the main tributary, that is for each part included between two sequential monitoring sections, allowing the definition of the environmental state; the results of the procedure are summarized in Figure 4. The ecological state resulted binding for environmental state classification because the chemical state was high for all the sections. Instead, Figure 3 shows the contribution of each macro-index for the achievement of the quality state for each section.

The water basin of the Sele river is characterized by both good environmental quality state in 5 of the 6 sections and moderate quality state in the remaining station. The quality of the river is uninfluenced by contributions of the tributaries corresponding to the $\mathrm{S} 2$, and S3 sections, characterized by good quality state.

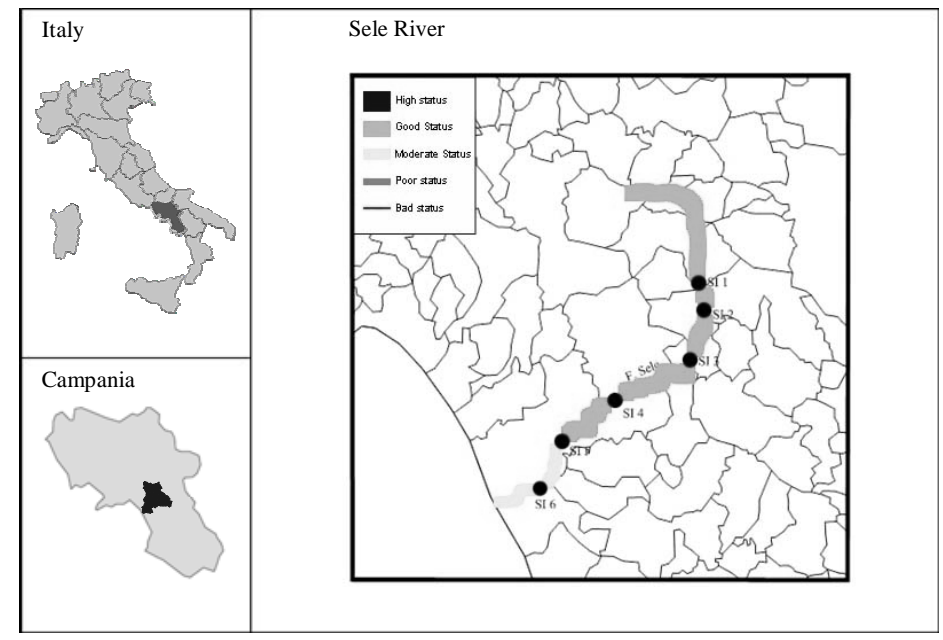

Figure 4. Territorial lay out of the Sele basin and the location of the river sampling sites

\section{CONCLUSIONS}

The WFD introduces a new combined approach to pollution control through integrating emission limit objectives that target point source pollutants with environmental quality objectives that monitor the receiving environment and target diffuse pollution. 
The integration of ecological indicators with more traditional water quality and quantity objectives will be a much bigger challenge. Following the WFD deadlines, Member States must produce national criteria for reversing pollution trends by 2006.

To assess the chemical and the ecological status of the surface water according to WFD2000, the approach of the EU Directive were discussed. The influences of the assessment methods on the water quality classes are also showed. In this context, a brief overview of chemical, physical, and biological monitoring methods, problems related to implementation of the new directive is done.

The implementation of the WFD in Italy using a case study as an example was described and discussed in this paper. The results obtained gave a preliminary chemical, physical and biological definition of the water quality of the hydrographic basin of the river Sele, as well as the relative classification with reference to the outlines set out by the WFD and upheld by the D.L.152/99. The basin of the river Sele resulted in having a "goodmoderate" environmental status, as well as having good self-depurating capacity, dealing with the polluting loads coming from waste water treatment plants located along the main tributary.

\section{REFERENCES}

1. Aramaki T. and Matsuo T. (1998). Evaluation model of policy scenarios for basin-wide water resources and quality management in the tone river, Japan. Wat. Sci. Tech., 38(11), 59-67.

2. Kamal M. M., Malmgren-Hansen A. and Badruzzaman A. B. M. (1999). Assessment of pollution of the river Buriganga, Bangladesh, using a water quality model. Wat. Sci. Tech., 40(2), 129-136.

3. Leaf S. S. and Chatterjee R. (1999). Developing a strategy on eutrophication. Wat. Sci. Tech., 39(12), 307-314.

4. Cate F. M. (1999). River Basin Management in Lower and Upper Austria: Beginnings and Future Prospects. Wat. Sci. Tech., 40(10), 185-193.

5. Fehér J., Galambos I. and Lehoczki Z. (1999).Water Quality Management Options for a Downstream Transboundary River Basin - The Sajó River Case Study. Wat. Sci. Tech., 40(10), 95-102.

6. Sekhar M. C. and Anand Raj P. (1995). Landuse - water quality modelling: a case study. Wat. Sci. Tech., 31(8), 383-386.

7. Crane M. (2003). Proposed development of Sediment Quality Guidelines under the European Water Framework Directive: a critique. Toxicology Letters, 142(3), 195-206.

8. Henocque Y. and Andral B. (2003). The French approach to managing water resources in the Mediterranean and the new European Water Framework Directive. Marine Pollution Bulletin, 47(1-6), 155-161.

9. Horn A. L., Rueda F. J., Hörmann G. and Fohrer N. (2004). Implementing river water quality modelling issues in mesoscale watershed models for water policy demands- an overwie on current concepts, deficits, and future tasks. Physics and Chemistry of the Earth, 29, 725-737.

10. La Jeunesse I., Rounsevell M., and Vanclooster M. (2003). Delivering a decision support system tool to a river contract: a way to implement the participatory approach principle at the catchment scale? Physics and Chemistry of the Earth, Parts A/B/C, 28(12-13), 547-554.

11. Mostert E. (2003). The European Water Framework Directive and water management research. Physics and Chemistry of the Earth, Parts A/B/C, 28 (12-13), 523-527.

12. Bongaerts J. C. (2002). European Water Law: water policy and water resources management in France: the projet de loi sur l'eau. European Environmental Law Review, 239-244.

13. Blöch H. (1999). The European Union Water Framework Directive: taking European water policy into the next millennium. Wat. Sci. Tech., 40(10), 67-71.

14. Kallis G. and Butler D. (2001). The EU Water Framework Directive: measures and implications. Water policy, 3(2), 125-142.

15. Barth F. and Fawell J. (2001). The Water Framework Directive and European Water Policy. Ecotoxicology and Environmental Safety, 40(2), 103-105.

16. Ausili A., Mecozzi M., Gabellini M., Ciuffa G and Mallara F. (1998). Physico chemical characteristics and multivariate analysis of contaminated harbour sediments. Wat. Sci. Tech., 37(6-7), 131-139. 